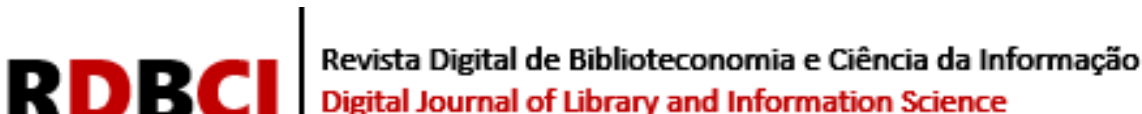 \\ Digital Journal of Library and Information Science
}

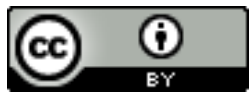

\section{A inovação nas bibliotecas universitárias em tempo de pandemia da Região Norte do Brasil}

\author{
Rejane Sales de Lima Paula ${ }^{1}$ iD https://orcid.org/0000-0002-1460-883X \\ Elaine da Silva ${ }^{2}$ (D) https://orcid.org/0000-0003-1449-354X \\ Luana Maia Woida ${ }^{3}$ https://orcid.org/0000-0003-3621-9154 \\ ${ }^{1}$ Universidade Federal de Rondônia, Porto Velho, RO, Brasil / e-mail: paula.rejane23@gmail.com \\ ${ }^{2}$ Universidade Federal de São Carlos, São Carlos, SP, Brasil / e-mail: elaine.silva1 @ unesp.br \\ ${ }^{3}$ Faculdade de Tecnologia de Garça, Garça, SP, Brasil / e-mail: luanamwoida@yahoo.com.br
}

\section{RESUMO}

Introdução: O novo cenário que estamos vivenciando tem nos chamado a repensar o papel da biblioteca como suporte educacional à universidade, pois, em uma sociedade organizada em torno das Tecnologias Digitais e Informacionais e Comunicacionais, ela deve desenvolver serviços e produtos digitais para atender as necessidades de informação da comunidade usuária interna e externa, visto que as Bibliotecas Universitárias (BU) na sociedade conectada são fundamentais para a produção do conhecimento científico e também para suprir as lacunas dos sujeitos diante da difusão do conhecimento. Este novo cenário tem obrigado o fechamento das bibliotecas no Brasil, especialmente nas Instituições Federais de Ensino Superior, no entanto, muitas delas vem se reinventando no oferecimento de serviços e produtos informacionais online, apesar dos desafios impostos, elas estão se adequando às mudanças ocorridas no decorrer dos tempos. Método: Este artigo trata-se de uma pesquisa qualitativa de natureza básica utilizando o método exploratório e descritivo, com revisão bibliográfica referente à temática de inovação nas bibliotecas universitárias. O resultado de pesquisa foi coletado nos websites das bibliotecas da região norte do Brasil. O levantamento dos dados permitiu um melhor entendimento da forma como as BU da região do Brasil estão atendendo as necessidades informacionais de seus usuários no período de pandemia da COVID-19. Conclusão: Apesar de algumas das BUs não estarem desenvolvendo ações voltadas para a capacitação de sua comunidade acadêmica, ainda há aquelas que vem apoiando as atividades acadêmicas através de atitudes inovadoras na sociedade contemporânea, como a oferta de serviços e produtos informacionais de forma diversificada.

PALAVRAS-CHAVE: Bibliotecas universitárias. Pandemia Covid-19. Ações inovadoras.

\section{Innovation in university libraries in a period of pandemic in the Northern region of Brazil}

\begin{abstract}
Introduction: The new scenario that we are experiencing has called us to rethink the role of the library as an educational support for the university, because, in a society organized around Digital and Informational and Communication Technologies, it must develop digital services and products to meet the needs of information from the internal and external user community, since the University Libraries (BU) in the connected society are fundamental for the production of scientific knowledge and also to fill the gaps of the subjects in the face of the dissemination of knowledge. This new scenario has forced the closure of libraries in Brazil, especially in the Federal Institutions of Higher Education, however, many of them have been reinventing themselves in offering services and information products online, despite the challenges imposed, they are adapting to the changes that occurred in the over time. Method: This article is a qualitative research of a basic nature using the exploratory and
\end{abstract}




\section{RDBCI}

descriptive method, with a bibliographic review on the theme of innovation in university libraries. The research result was collected on the websites of libraries in the northern region of Brazil. The survey of the data allowed a better understanding of the way in which BUs in the region of Brazil are meeting the information needs of their users during the pandemic period of COVID-19. Conclusion: Although some of the BUs are not developing actions aimed at training their academic community, there are still those that have been supporting academic activities through innovative attitudes in contemporary society, such as offering information services and products in a diversified way.

KEYWORDS: University libraries. Covid-19 Pandemic. Innovative.

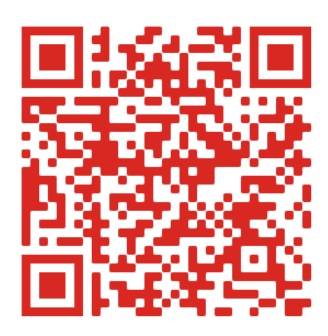

JITA: DD. Academic libraries 


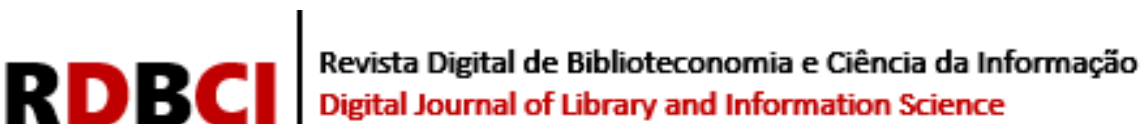

\section{INTRODUÇÃO}

Atualmente estamos convivendo com o fechamento das Bibliotecas Universitárias (BU), que são os principais centros disseminadores de informação nas Instituições Federais de Educação Superior (IFES), isto devido ao enfrentamento ao COVID-19 que "[...] é uma doença causada pelo coronavírus, denominado SARS-CoV-2, que apresenta um espectro clínico variando de infecções assintomáticas a quadros graves" (BRASIL, 2020, p. 1). Diante disso, a Organização Mundial da Saúde (OMS) declarou, em 11 de março de 2020, que a COVID-19 foi considerado como um surto pandêmico, e os primeiros surtos da doença ocorreram na cidade de Wuhan, na China, em dezembro de 2019. Desde então, a COVID-19 vem assolando o mundo inteiro, especialmente o Brasil que já soma mais de 126 mil óbitos ${ }^{1}$, e isto tem imposto à sociedade em geral o isolamento social e a quarentena a fim de evitar a expansão e o contágio de pessoa a pessoa, visto que sua transmissão acontece por meio de gotículas, e a maioria dos infectados pela COVID-19 desde infecções assintomáticas a quadros graves.

No Brasil, das "69 universidades federais, 60 suspenderam encontros presenciais" devido ao COVID-19, as Instituições Federais de Ensino Superior (IFES), tomaram essa decisão para o bem da comunidade acadêmica e da sociedade em geral, mas, apesar do fechamento por tempo indeterminado, muitos docentes e técnicos administrativos continuam em teletrabalho para não paralisar as atividades da universidade que apoiam o ensino, pesquisa e extensão (JUNQUEIRA; BALDRIGHI, 2020, p. 1). Em vista disso, Tanus e Tarragó (2020) tecem que, uma vez que, "as universidades não só estão orientadas para a comunidade acadêmica, mas também têm a missão de transferir conhecimentos e serviços para toda a sociedade" (TANUS; TARRAGÓ, 2020, p. 4). Sendo assim, esse cenário tem incitado as BU inovarem com a prestação de serviços e produtos informacionais, visto que, elas são um dos pilares da educação superior servindo de apoio para o ensino, à pesquisa e a extensão, e por isso, estão se reinventando no cenário atual ao ofertarem serviços e produtos informacionais como empréstimos de livros de forma delivery, treinamentos, oficinas, lives de competência em informação de como utilizar as fontes informacionais de forma segura para pesquisa, normatização de trabalhos acadêmicos, escrita científica dentre outros. Para Neves (2018, p. 23), considera estes serviços e produtos informacionais como "ferramentas de aprendizado para enriquecimento intelectual, portanto, faz-se necessário a biblioteca a capacidade de inovar". Diante disso, vale ressaltar que as BU são fundamentais para a produção do conhecimento científico e também para suprir as lacunas dos sujeitos diante do universo informacional, sendo que "dentro das universidades, são as bibliotecas as entidades capazes de articular a rede de troca de informações que servirá a membros da comunidade universitária e público externo" (TANUS; TARRAGÓ, 2020, p. 4). No entanto, de acordo com a Comissão Brasileira de Bibliotecas Universitárias (CBBU) e a Federação Brasileira de Associações de Bibliotecários, Cientistas de Informação e Instituições das Bibliotecas (FEBAB) $)^{2}$ destacam que algumas BU "não conseguiram acompanhar as mudanças ocorridas devido ao COVID-19, pois tiveram que interromper todos os seus serviços, o que poderá gerar uma grande demanda de serviços das bibliotecas na reabertura, aumentando assim o risco de contágio", como exemplo, empréstimo e devolução de livros (CBBU, 2020, p. 1). Com base nessa realidade surge o seguinte questionamento, por que algumas BU conforme citado pela CBBU (2020) estão enfrentando tantas barreiras diante da pandemia, se as Tecnologias da Informação e Comunicação (TIC)

\footnotetext{
${ }^{1}$ Dados coletado em 07 de setembro de 2020. Disponível em: https://covid.saude.gov.br/

2 Recomendações da Comissão Brasileira de Bibliotecas - CBBU para elaboração de planejamento de reabertura das bibliotecas universitárias. Disponível em: http://www.febab.org.br/cbbu/wp-content/uploads/2020/05/Recomenda\%C3\%A7\%C3\%B5es-14-de-maio-1.pdf
} 


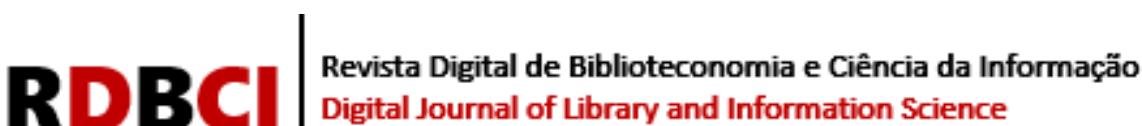

tendem a facilitar o acesso aos repositórios institucionais, as bibliotecas digitais e às bases de dados, treinamentos, oficinas, webinar, dentre outros produtos e serviços que podem ser disponibilizados online à comunidade acadêmica e sociedade em geral? Para Santa Anna (2015), "o uso dessas tecnologias viabiliza a disseminação da informação e a produção de conhecimento, aumentando a capacidade das bibliotecas para a democratização da informação, rompendo barreiras geográficas e temporais". Este autor ainda defende que as bibliotecas "mesmo passando por desafios e inúmeras mudanças, essas instituições sobrevivem graças à capacidade de adequação às constantes transformações ocorridas ao longo dos tempos" (SANTA ANNA, 2015, p. 138). Tendo em vista esse panorama, torna-se importante enfatizarmos sobre os fatores culturais e crenças existentes nas bibliotecas universitárias que as impedem de se adaptarem ao novo cenário. Apesar das BU ser aparentemente "homogêneas, as bibliotecas se diferenciam, em maior ou menor grau, exatamente no campo da cultura" (SANTOS, 2016, p. 90). Assim sendo, percebe-se que algumas BU apresentam posturas distintas como afirma a CBBU (2020), e estas questões vem de encontro com a cultura organizacional, uma vez que, "toda organização tem sua própria história e na medida em que se estrutura, adquire identidade, tradições e padrões de comportamento, passando a delinear os valores" (DUARTE, et al., 2000, p. 2).

Para Almeida Júnior (2018, p. 52), a cultura é definida como, "algo que vem sendo construídas historicamente e sempre vinculadas à sociedade, às transformações, mudanças, alterações sociais. E mais: abrange o modo de vida de uma sociedade, os valores, as normas, os gestos, os comportamentos [...]". Nesse sentido, podemos verificar que o aparato tecnológico não surtirá efeito nas bibliotecas universitárias se o corpo técnico administrativo não substituir valores, crenças e rituais culturais inadequados para uma nova realidade, visto que, têm muitos que ainda não se adaptaram às mudanças, e isto, tem sido umas das barreiras que as bibliotecas vêm enfrentando no período da pandemia de COVID-19. Contudo, deve-se considerar também a falta de recursos financeiros para o não oferecimento de serviços e produtos informacionais. No entanto, há muitas bibliotecas universitárias que estão preparadas para atender com serviços e produtos digitais a sociedade hodierna, visto que, os reflexos da pandemia nas BU nas IFES, vêm evidenciando as transformações oriundas e que são necessárias nesse novo cenário o qual tem exigido profissionais bibliotecários competentes em informação para fazer uso das Tecnologias Digitais de Informação e Comunicação (TDIC) como fonte de informação, considerando que as BU têm um papel muito relevante na democratização e acesso à informação.

A partir disso, surge o seguinte questionamento: quais as ações inovadoras das bibliotecas universitárias da Região Norte do Brasil em tempo pandêmico? Para responder essa questão, analisamos os websites das BU para identificar as ações inovadoras dos serviços e produtos digitais que são oferecidos à comunidade acadêmica e a sociedade em geral.

\section{PROCEDIMENTO METODOLÓGICO}

Este trabalho trata-se de uma pesquisa de cunho exploratório-descritiva e de natureza básica. A pesquisa exploratório-descritiva conforme Marconi e Lakatos (2013, p. 71), "são estudos exploratórios que têm por objetivo descrever completamente determinado fenômeno". Quanto à relevância da pesquisa ser de natureza qualitativa básica, esta é denominada assim por produzir conhecimentos gerais, úteis para o avanço da ciência, sem uma aplicação prática prevista inicialmente, envolvendo verdades e interesses universais, quando "permite articular conceitos e sistematizar a produção de uma determinada área de conhecimento" (MINAYO, 


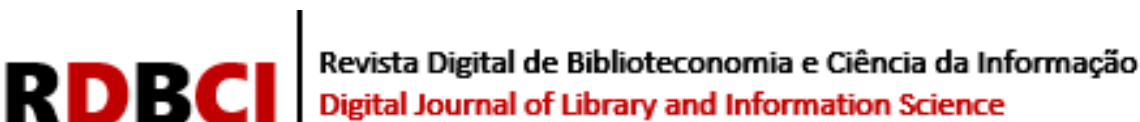

2002, p. 52). Para Marconi e Lakatos (2008, p. 269), “[...] o método qualitativo difere do quantitativo não só por não empregar instrumentos estatísticos, mas também pela forma de coleta e análise dos dados". Diante do exposto, optamos neste estudo focar nos serviços e produtos informacionais oferecidos pelas $\mathrm{BU}$, assim, os dados da pesquisa serão coletados e extraídos dos websites das BU da região norte do Brasil (Acre, Amapá, Amazonas, Pará, Rondônia, Roraima e Tocantins).

\section{O BIBLIOTECÁRIO E O SEU PAPEL NA CONTEMPORANEIDADE}

A sociedade hodierna vem exigindo do profissional bibliotecário conhecimentos especializados para o uso e o domínio da informação em qualquer formato, físico ou digital, já que elas se caracterizam pelos princípios da diversidade, da integração e da complexidade. Diante disso, o profissional bibliotecário precisa realizar a busca contínua de aperfeiçoamento para que possua "habilidades para encontrar, avaliar, interpretar, criar e aplicar a informação disponível na geração de novos conhecimentos" e possa ainda atuar de forma criativa e proativa, entre outras coisas em suas unidades de informação, especialmente no contexto da educação superior, em relação aos aspectos que cercam o acesso e o uso da informação para a formação dos sujeitos na sociedade da informação (BELLUZZO; KOBAYASHI; FERES, 2004, p. 95). Para Araújo e Dias (2011) o bibliotecário tem como função desempenhar no contexto educacional a criação de serviços e produtos que visem o gerenciamento da informação, de modo a oferecer subsídios para o sujeito acessar e obter informações de acordo com sua necessidade, levando em consideração o uso ético da informação nas pesquisas e produções científicas, pois de acordo com Rios (2008, p. 79), isto é, “[...] uma dimensão fundante do trabalho de boa qualidade" desses profissionais. Mediante estas considerações, ressaltamos que os bibliotecários nas bibliotecas universitárias têm como função mediar a informação e a competência em informação. As funções dos bibliotecários nas bibliotecas universitárias são confirmadas por Alves, Casarin e Fernandéz-Molina (2016, p. 116), quando defendem que:

\footnotetext{
Os bibliotecários universitários podem trabalhar com as implicações ético-legais e o combate ao plágio na realidade de suas unidades de informação, em especial em ações educativas que promovam o desenvolvimento da Competência Informacional e nas discussões a respeito dos aspectos éticos na produção científica com outros setores da instituição.
}

Desta forma, o papel do bibliotecário não é apenas auxiliar o usuário a obter a informação desejada, mas, também de intervir na formação do sujeito criando meios para facilitar o acesso e o uso da informação de forma ética e responsável. Por esta razão, Freire (2002) aponta a educação como uma forma de intervenção no mundo, ela não é somente para a transmissão de conhecimentos e, sim para criar possibilidades de produzir e construir saberes. É nessa perspectiva, que Alves (2018, p. 16), enfatiza a importância do desenvolvimento da competência informacional no contexto educativo, sobretudo em relação aos aspectos que cercam o acesso e o uso da informação para a formação dos sujeitos na sociedade da informação. Nesta linha de pensamento, Coelho Neto (1996, p. 5), destaca que "o papel do bibliotecário na sociedade está se alterando devido às novas tecnologias de informação e comunicação. Novas formas de trabalhar surgiram porque novas ferramentas foram criadas para o controle, organização e disseminação da informação". Nesse contexto é importante levar em consideração a fala de Almeida Júnior (2015, p. 25), quando enfatiza que "toda ação de interferência realizada em um processo, por um profissional da informação e na ambiência de 


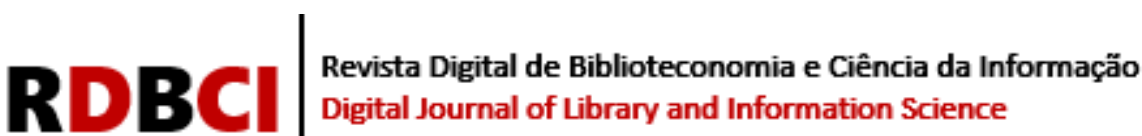

equipamentos informacionais" visa estratégias de modo a propiciar suporte informacional à educação e à formação da comunidade usuária e a sociedade em geral. Pois segundo Brito e Vitorino (2017, p. 12), "a forma de atuação e o perfil do bibliotecário influencia e pode determinar o sucesso ou não do processo de aquisição do conhecimento pelos mediados, contribuindo assim para a sua formação".

Nesse sentido, é pertinente evidenciar que o bibliotecário ${ }^{3}$ é um profissional da informação que deve estar capacitado a "atender as necessidades informacionais de todos os usuários, sejam de bibliotecas, ou de qualquer centro de documentação", capaz de disseminar, orientar e ensinar os sujeitos de como utilizar de forma eficiente e ética as informações disponíveis tanto na rede mundial de computadores, como também dentre outros suportes informacionais (SALES, 2004, p. 40). Sob essa perspectiva, consideramos que o papel do bibliotecário nas bibliotecas universitárias é mediar a informação seja ela física ou digital, e capacitar os sujeitos para o trato com a informação, onde o profissional bibliotecário "deve dispor aos usuários a informação atualizada e com qualidade" (CORDEIRO; CUNHA; PARGA, 2015, p. 100).

Para tanto, o bibliotecário no ambiente acadêmico tem por finalidade desenvolver a competência em informação, ao "incentivar o desenvolvimento da autonomia do usuário para a aquisição de uma série de habilidades transversais necessárias para classificar e avaliar as informações e as suas fontes" (AZEVEDO, OGÉCIME, 2020, p. 5). Sendo assim, as BU são fundamentais para a produção do conhecimento científico e também para suprir as lacunas dos sujeitos diante do universo informacional, sendo que "dentro das universidades, são as bibliotecas as entidades capazes de articular a rede de troca de informações que servirá a membros da comunidade acadêmica e público externo" (TANUS; TARRAGÓ, 2020, p. 4). Por isso, Prado e Cavaglieri (2016, p. 95), tecem que os profissionais bibliotecários devem sempre se reinventar para que possam oferecer para a comunidade acadêmica e a sociedade em geral nas bibliotecas universitárias o uso das fontes de informação disponíveis, visto que, "a inovação passa a acontecer nas bibliotecas quando estas percebem que somente os registros informacionais bibliográficos já não atenderão uma sociedade conectada, participativa e com acesso rápido e vasto a uma variedade de recursos".

Diante disso, discorreremos a respeito do bibliotecário como mediador da informação nas bibliotecas universitárias. Este assunto vem sendo discutido na área da Ciência da Informação e Biblioteconomia com objetivo de provocar reflexões à atuação deste profissional, como afirma Gomes (2014, p. 47), "de modo central esses estudos têm se ocupado da abordagem conceitual, dos fundamentos teóricos, do delineamento dos tipos de mediação, das categorias de atividades de mediação e do papel mediador do profissional da informação". Partindo disso, aborda-se a respeito da inovação dos serviços e produtos informacionais nas BU, estas ações são desenvolvidas pelo profissional bibliotecário para oportunizar a comunidade acadêmica e a sociedade em geral o acesso à informação durante processo formativo.

\footnotetext{
3 A profissão do bibliotecário é regulamentada pela Lei 4.084/62, e pela Lei 9.674/98, que dispõe sobre o exercício de sua profissão.
} 


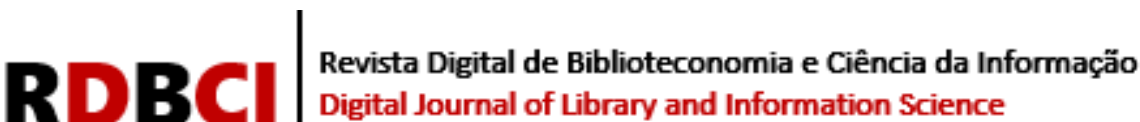

\section{A INOVAÇÃO NOS SERVIÇOS E PRODUTOS DAS BIBLIOTECAS UNIVERSITÁRIAS}

A inovação é uma das propulsoras para a competitividade nas IFES, isto em consequência da modernidade e das transformações que vem ocorrendo na educação superior, considerando que as "as tecnologias são consideradas necessárias para contribuir com o processo de organização, recuperação e transmissão da informação" (GOMES; DUMONT, 2015, p. 133). Diante disso, as bibliotecas universitárias precisam se adaptar às alterações provocadas por essas mudanças que são intrínsecas a educação superior e assim, oferecer serviços e produtos informacionais para a pesquisa, ensino e extensão de modo a melhorar a educação do sujeito em formação. Para Neves (2018, p, 24), "a inovação é o requisito primordial para a competitividade e sobrevivência das organizações, de maneira que sua manifestação é efetivada principalmente por meio de produtos e serviços oferecidos". Nesta perspectiva as BU são incitadas a inovar para oferecer aos seus usuários e a sociedade em geral serviços e produtos informacionais online, para tanto, elas devem ter estratégias e focar nas necessidades dos usuários para que possam inovar e satisfazer a comunidade acadêmica com as informações provenientes de seu interesse.

De acordo com o Manual de Oslo (2005), a "inovação pode, previamente, ocorrer em qualquer setor da economia, inclusive em serviços públicos como saúde ou educação" (OCDE, 2005, p. 19). Sendo assim, para que as inovações sejam engajadas nas BU, estas devem visar primeiramente o desenvolvimento do seu capital intelectual, pois, os fatores internos influenciam a inovação, pois como afirma Loures (2006, p. 38), "[...] sem sujeitos inovadores, não há inovação e nesse aspecto a dimensão humana é o fator principal do processo inovador; sujeitos inovadores são criativos, portanto a criatividade é condição para inovação".

O Manual de Oslo (2005) ainda ressalta que, "empregados capacitados são considerados um recurso-chave de uma empresa inovadora. Sem trabalhadores capacitados a empresa não conseguirá dominar novas tecnologias e, muito menos, inovar" (OCDE, 2005, p. 41). Para Nascimento, Filho e Barros (2005, p. 6), "o bom funcionamento e o sucesso de uma unidade de informação dependerão da correta organização do gestor". Já Neves (2018) destaca que a inovação no contexto das bibliotecas universitárias, a priori deve começar pela valorização e o desenvolvimento dos bibliotecários, uma vez que sem uma equipe inovadora não é possível satisfazer usuários das bibliotecas ${ }^{4}$.

Para Zaninelli, Nogueira e Horimi (2019, p. 232), "o ambiente organizacional tem muita influência sobre o tipo de ações inovadoras que ocorrem", daí surge o questionamento, as BU estão inovando com seus serviços e produtos informacionais? Ou estão apenas oferecendo serviços e produtos rotineiros de suas atividades? Diante disso, Zaninelli, Nogueira e Peres (2019, p. 12), afirmam que, "apesar da finalidade das BU permanecer a mesma com o passar dos anos, os processos utilizados no oferecimento de serviços e produtos mudaram, visto que as transformações tecnológicas causaram alterações em tais unidades", desse modo, podemos considerar que as BU a cada dia vem se reinventando nesse novo tempo de pandemia, elas estão se reinventando ultrapassando as paredes, buscando atender usuários e a sociedade em geral com treinamentos virtuais, Webinar, liberação de acesso às bibliotecas digitais, entre outros.

De acordo com a Organização para a Cooperação e Desenvolvimento Econômico (OCDE), "inovação é a implementação de um produto (bem ou serviço) novo ou melhorado. Ou um processo. Ou um novo método de marketing. Ou um novo método organizacional nas

\footnotetext{
4 Não iremos nos deter em descrever sobre a valorização e desenvolvimento do bibliotecário nas BU, pois este não é o foco deste trabalho. Para saber mais sobre o assunto sugere-se a leitura do trabalho de NEVES (2018).
} 


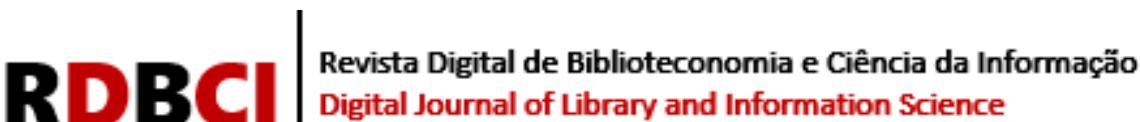

práticas de negócios" (OCDE, 2005, p. 54-55). Considerando este novo cenário de pandemia da COVID-19, que vem determinando às BU novas maneiras de oferecer seus serviços e produtos por meio das TDIC, tem-se o uso das mídias sociais, os canais de comunicação interativo, os Webinar, as videoconferências, dentre outras ferramentas existentes ofertando o acesso e disseminação da informação científica. Inferimos que os serviços não são apenas rotineiros, mas também uma nova forma de desenvolver por meio desses recursos e ferramentas a mediação da informação, trazendo a tona o papel social das bibliotecas universitárias.

Segundo Prado e Cavaglieri (2016, p. 95-96), “a inovação passa a acontecer nas bibliotecas quando estas percebem que somente os registros informacionais bibliográficos já não mais atenderão uma sociedade conectada, participativa e com acesso rápido e vasto a uma variedade de recursos". Assim, a BU tem se engajado a aprimorar seus serviços e produtos informacionais, ao disponibilizar informações através dos websites, das redes e mídias sociais, como Instagram, Twitter, Facebook e outros meios de comunicação. Esses meios de comunicação são grandes disseminadores de informação e onde vários sujeitos estão conectados diariamente, fazendo com que as informações circulem em maior velocidade, pois esses canais informacionais permitem que bibliotecários e usuários não somente busquem a interação, mas também que façam compartilhamento de informações. Para Zaninelli, Nogueira e Horimi (2019, p. 229):

A inovação em estrutura e serviços é algo que deve ser pensado, pois atrair e manter usuários em uma biblioteca é cada vez mais um desafio. Dessa forma, para que as organizações do setor de serviços - especialmente as bibliotecas - obtenham o sucesso, é fundamental que as mesmas considerem: (1) novas formas de abordagens aos usuários e (2) novos processos de desenvolvimento e entrega dos seus serviços, devem reavaliar seu "serviço central/principal", que atualmente volta-se para a oferta e disponibilização da informação, e, portanto, conseguirem efetivamente inovar os serviços atualmente fornecidos, dando oportunidade de escolha aos usuários que frequentam os espaços das bibliotecas, para que os mesmos possam sim suprir as suas necessidades informacionais, mas também poderem olhar a biblioteca como um espaço de cultura, lazer e entretenimento.

Nesse âmbito, Zaninelli, Nogueira e Peres (2019, p. 13), evidenciam que "as BU devem centralizar seus serviços nos diversos perfis de seus usuários, de forma aliada à estratégia da universidade e às tendências conjunturais da sociedade da informação". A esse respeito, levando em consideração o atual cenário epidêmico que estamos vivenciando, as BU têm procurado maneiras de disponibilizar a informação ao fomentar ao seu usuário real ou potencial $^{5}$ meios de obterem acesso aos serviços e produtos informacionais oferecidos. Essas autoras ainda citam (p. 14) que três bibliotecas no Brasil conseguiram inovar seus serviços e produtos de acordo com a necessidade de seus usuários, como a Biblioteca da Universidade Federal de Goiás (UFG), que oferece o Programa de Capacitação de Usuários (treinamento do Portal da Capes, treinamento de uso da biblioteca e das fontes de informação), a Universidade Federal de Santa Catarina (UFSC) que possui o serviço "Biblioteca das Coisas ${ }^{6}$ e o BookCrossing $^{7}$, e por fim a Universidade de São Paulo (USP) que oferece o serviço de "Empréstimo Entre Bibliotecas (EEB) e o aplicativo móvel SIBiUSP, que permite realizar

\footnotetext{
${ }^{5}$ Usuários reais são definidos como aqueles que utilizam os serviços, e usuários potenciais como o total de usuários que podem utilizar o serviço de informação (DIAS, et al., 2004, p. 7). Disponível em: https://bibliotextos.files.wordpress.com/2012/12/usos-e-usuc3a1rios-da-informac3a7c3a3o.pdf.

${ }^{6}$ Oferece o empréstimo de itens além de livros, como calculadoras, guarda-chuvas, notebooks, carregadores de celulares e adaptadores, dentre outros (ZANINELLI; NOGUEIRA; PERES, 2019, p. 14).

${ }^{7}$ Prática de deixar um livro num local público (no caso, um espaço reservado pela biblioteca), para que seja encontrado e lido por outro usuário, que deverá fazer o mesmo (ZANINELLI; NOGUEIRA; PERES, 2019, p. 14).
} 


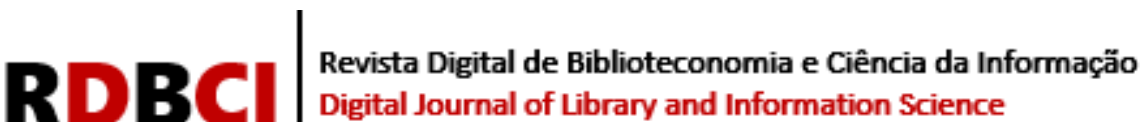

buscas por um livro, encontrar a biblioteca da USP que o possui e verificar sua disponibilidade" (ZANINELLI; NOGUEIRA; PERES (2019, p. 14-15).

Considerando essas inovações especificadas por Zaninelli, Nogueira e Peres (2019), podemos afirmar que algumas das BU da região norte do Brasil também vem inovando com serviços e produtos informacionais oferecidos para a comunidade acadêmica, que serão destacados na seção 5 .

\section{AÇÕES INOVADORAS NAS BIBLIOTECAS UNIVERSITÁRIAS DA REGIÃO NORTE DO BRASIL}

A região Norte do Brasil é composta por sete estados (Acre, Amapá, Amazonas, Pará, Rondônia, Roraima e Tocantins), os sete estados possuem IFES que são compostas por BU que são "instância que possibilita à universidade atender às necessidades de um grupo social ou da sociedade em geral, através da administração do seu patrimônio informacional e do exercício de uma função educativa". Diante disso, será destacado a seguir os serviços e produtos informacionais oferecidos a comunidade acadêmica e a sociedade em geral, que segundo Almeida et al. (2016, p. 18), estes serviços podem ser considerados inovadores, pois a "[...] produção de algo novo, de natureza pessoal, empresarial ou institucional, de caráter objetivo ou subjetivo, tangível ou intangível, mensurável ou imensurável", sendo assim, considerando a necessidade das bibliotecas universitárias de se reinventarem neste novo cenário pandêmico de coronavírus que vem devastando o mundo inteiro, as bibliotecas estão conseguindo desenvolver ações de acesso à informação.

A Universidade Federal do Acre possui 01 Biblioteca Central no Campus Sede, 01 Biblioteca Setorial no Campus Floresta e 04 Bibliotecas Setoriais nos Núcleos dos municípios de Brasiléia, Feijó, Sena Madureira, Tarauacá e Xapuri (em fase de implantação) e 01 Biblioteca Escolar no Colégio de Aplicação, em Rio Branco. Em pesquisa no website da Biblioteca Central da UFAC ${ }^{8}$ foi verificado que não foi criado nenhuma ação de oferecimento de serviço e produto informacional à comunidade acadêmica em tempo de pandemia do COVID-19, como treinamentos virtuais, Webinar, palestras, oficinas, dentre outros. No website também não consta agendamento para atendimento ao usuário, nem informativos a respeito de serviços e produtos que a comunidade acadêmica pode solicitar online ou da interrupção de recebimentos de livros emprestados antes da pandemia. Também não conseguimos constatar a data inicial de quando a BU interrompeu o fornecimento de seus serviço e produto informacional à comunidade acadêmica e a sociedade em geral. Por não encontrarmos informações no website da BU da UFAC sobre serviços informacionais à comunidade nesse cenário de pandemia enviamos e-mail dia 05/08/2020 perguntando se estava disponibilizando algum serviço ou produto informacional a comunidade interna ou externa, bem como se estavam em teletrabalho, no entanto não obtivemos resposta.

A Universidade Federal do Amapá consta com um Sistema de Biblioteca, totalizando 05 unidades, composta pela Biblioteca Central, Biblioteca Binacional do Campus Oiapoque, Biblioteca do campus de Santana, Biblioteca do Campus de Mazagão e uma biblioteca setorial de saúde que está em construção. No website do Sistema de Biblioteca UNIFAP ${ }^{9}$ não encontramos nenhuma ação criada destinada a atender a comunidade acadêmica e sociedade em geral em tempo de pandemia do COVID-19. No website da UNIFAP consta sinalizadas

8 Consulta no Website http://www2.ufac.br/biblioteca, realizada em 01/08/2020.

${ }^{9}$ Consulta no Website https://www2.unifap.br/biblioteca/, realizada em 01/08/2020. 


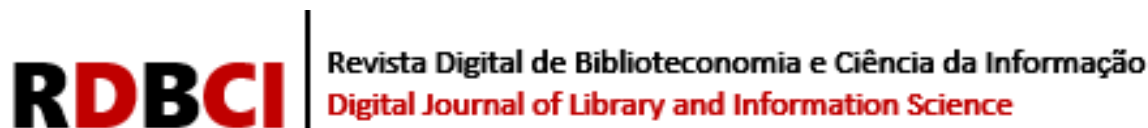

informação necessária referente à equipe da BU, uma galeria de fotos e fale conosco. Verificamos que no Sistema de biblioteca da UNIFAP apenas consta os serviços e produtos de rotina como a elaboração de ficha catalográfica, consulta ao acervo, empréstimo domiciliar realizado via SIGAA. No website da biblioteca também consta uma agenda para a solicitação de uso do auditório, bem como uma agenda para a solicitação de treinamentos, periódicos e plataformas digitais, que é composto pelo Portal da Capes, periódicos da UNIFAP, 1findr e Microsoft acadêmico. Constatamos que a Biblioteca Central da UNIFAP possui perfil nas redes sociais, e está com informações atuais no Facebook e Instagram, já no Twitter o último post foi em 2015. Não encontramos informação referentes às outras bibliotecas do sistema da UNIFAP no website. Conseguimos localizar no website e nas redes sociais o horário de atendimento da BU, telefone e e-mail da diretoria da Biblioteca Central, sem informação das demais bibliotecas dos campi pertencentes à universidade. Confirmamos que o Sistema de Bibliotecas da UNIFAP interage com a comunidade acadêmica via Facebook e Instagram.

Como não conseguimos localizar no website da BU nenhuma ação voltada para a comunidade acadêmica, enviamos no dia 05/08/2020 um e-mail a BU da UNIFAP referente às ações que estavam desenvolvendo e também perguntamos se os profissionais bibliotecários estavam em teletrabalho, porém, não obtivemos resposta.

A Universidade Federal do Amazonas é composta por uma Biblioteca Central, sete Bibliotecas Setoriais instaladas em Manaus e cinco Bibliotecas nas Unidades fora da sede, no interior do Estado. As sete Bibliotecas Setoriais contam com seus acervos informatizados e as cinco Bibliotecas das Unidades fora da sede estão com seus acervos parcialmente informatizados. O SISTEBIB utiliza o Sistema Pergamum de Gerenciamento de Bibliotecas (SISTEBIB/UFAM, 2020). O SISTEBIB da UFAM ${ }^{10}$ vem oferecendo à comunidade acadêmica e a sociedade em geral vários treinamentos, oficinas, Webinars, Liberação do acesso gratuito à Biblioteca Digital Cengage e acesso aos E-books da Elservier, conforme destacado nas Notícias. No website oficial também constam sinalizados as ferramentas de apoio ao ensino e os recursos informacionais (fontes de informação, catálogo online, repositório, BTDT, portal de periódicos da UFAM, portal de periódicos da Capes, revista de acesso Livre, Portal brasileiro de publicações científicas em acesso aberto - OASISBR, catálogo de teses e dissertações da Capes, dentre outros). Algumas das bibliotecas do SISTEBIB da UFAM possuem perfil no Facebook e Instagram (redes sociais). $\mathrm{O}$ atendimento presencial e a circulação de material bibliográfico no SISTEBIB da UFAM encontram-se suspensos em todas as bibliotecas, e as devoluções de materiais bibliográficos devem ser agendados previamente. No site da Biblioteca também estão disponíveis todos os e-mails das bibliotecas setoriais, bem como, canais de chat on-line e e-mail ${ }^{11}$ a disposição da comunidade interna e externa para caso de dúvidas ou informações essenciais.

A Universidade Federal do Pará é composta por 36 bibliotecas, a saber: 12 dos Institutos, 4 dos Núcleos, 2 dos Programas de Pós-graduação, 1 de Faculdade e 6 das Unidades Acadêmicas Especiais e, ainda, nos 10 campi dos municípios encontram-se as bibliotecas de: Abaetetuba, Altamira, Ananindeua, Bragança, Breves, Cametá, Castanhal, Salinópolis, Soure e Tucuruí. A maioria delas está localizada no campus Belém, enquanto as demais se distribuem nos campi de outros municípios. As bibliotecas adotam o software Pergamum e seus acervos estão integrados em um catálogo único, disponibilizado online. O SIBI/UFPA ${ }^{12}$ disponibiliza a comunidade acadêmica e à sociedade em geral, serviços de informação como o catálogo on-line do acervo das bibliotecas da UFPA; Portal de Periódicos da Capes (CAPES); Biblioteca Digital

\footnotetext{
10 Consulta no Website https://biblioteca.ufam.edu.br, realizada em 01/08/2020.

11 tibc@ufam.edu.br

12 Consulta ao Website http://bc.ufpa.br/, realizada em 05/08/2020.
} 


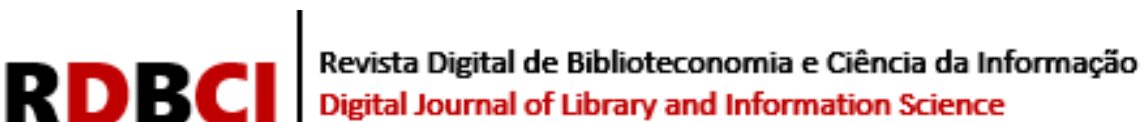

de Teses e Dissertações (BDTD); Repositório Institucional (RIUFPA); Portal do Livro Aberto; Biblioteca de Digital de Monografias; bases de dados do Instituto Brasileiro de Informação em Ciência e Tecnologia (IBICT); Biblioteca Virtual em Saúde (BVS); e outras bases de dados e serviços e produtos disponíveis na internet (SIBI/UFPA, 2020).

No website do SIBI/UFPA consta informado o horário de abertura e fechamento, bem como a relação de todas as bibliotecas universitárias com seus respectivos responsáveis. O que chama atenção neste website é a relação de todos os diretores da BU desde 1966 a 2016. E ainda é destacado ao acessar o website os canais de comunicação (WhatsApp) e as redes sociais (Facebook, Instagram, Twitter e canal no YouTube), além desses recursos informacionais o SIBI/UFBA possui em seu website o direcionamento para blogs, canal Youtube e revistas da área de Biblioteconomia e Ciência da Informação. Outro fator que chama atenção no SIBI/UFPA é o Plano de contingência - Covid-19, especificando todas as regras de cuidados e segurança conforme as orientações das autoridades sanitárias e as recomendações do Grupo de Trabalho da UFPA sobre o Novo Coronavírus, bem como os procedimentos para atendimento ao usuário que deve ser agendado, e ainda destaca o atendimento virtual via: Facebook, Instagram, WhatsApp e Fale Conosco. Consta também informado no plano de - Covid-19, que as BU adotarão o distanciamento social com as seguintes orientações aos usuários: Limitar o número de pessoas dentro da BC; Manter dispenser de álcool em gel pelos ambientes da BC; Obrigatoriedade de uso de máscara ao entrar na $\mathrm{BC}$; e ainda a higienização dos ambientes e do acervo.

O website da SIBI/UFPA é bem sinalizado quanto a disponibilização dos serviços e produtos oferecidos online, como Ficha catalográfica; Guia de Elaboração de Trabalhos Acadêmicos; Portal de Periódicos CAPES; Repositório Institucional; Biblioteca Digital de Monografias; Portal do Livro Aberto. Também consta a relação dos treinamentos, oficinas, eventos e lives que estão sendo realizadas pelo SIBI/UFPA em formato online.

A Universidade Federal de Rondônia tem em sua composição 8 bibliotecas, a saber: 1 sendo a biblioteca central na cidade de Porto Velho e 7 bibliotecas setoriais nas seguintes cidades: 1 em Cacoal, 1 em Ariquemes, 1 em Guajará-Mirim, 1 em Presidente Médici, 1 em Ji-Paraná, 1 em Vilhena e 1 em Rolim de Moura. As bibliotecas fazem parte de um sistema. Cada BU possui seu website próprio e rede sociais (Facebook e Instagram). A BU e suas setoriais estão disponibilizando em conjunto para toda a comunidade acadêmica e sociedade em geral treinamentos virtuais, palestras, lives, webinar, oficinas e eventos online. Assim, o SIBI/UNIR ${ }^{13}$ disponibiliza vários serviços e produtos informacionais para apoio ao ensino e pesquisa, além de canais de comunicação no YouTube. O SIBI/UNIR está atendendo de forma remota os serviços de Orientação sobre normas para trabalhos acadêmicos; Levantamento bibliográfico; Acesso a bases de dados; Treinamentos; Ficha catalográfica e Declaração de Quitação (Nada Consta) (SIBI/UNIR, 2020).

A Universidade Federal de Roraima possui três bibliotecas universitárias, a Biblioteca Central, a Biblioteca Setorial do CCA e a Biblioteca Setorial do Campus Murupu. No website da BU da UFRR ${ }^{14}$ está informado o horário de abertura e fechamento, bem como seus respectivos responsáveis e a relação de todos os servidores que estão lotados na BU. Também está disponível o catálogo online, acervo digital, serviços e multimeios oferecidos online. Com a pandemia a BU passou a oferecer treinamentos das pesquisas em bases de dados, portal de periódicos da Capes e biblioteca digital da UFRR via webconferência (BU UFRR, 2020).

13 Consulta ao Website http://www.bibliotecacentral.unir.br, realizada em 05/08/2020.

14 Consulta ao Website http://www.bc.ufrr.br, realizada em 06/08/2020. 


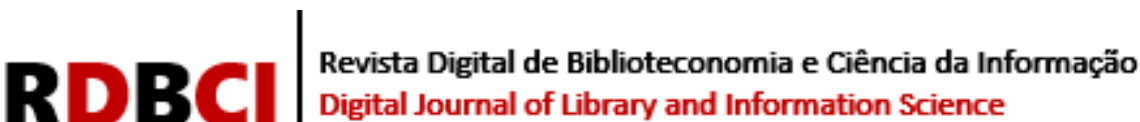

A Universidade Federal de Tocantins compreende as bibliotecas dos campi de Araguaína, Arraias, Gurupi, Miracema, Palmas, Porto Nacional e Tocantinópolis. No website oficial da BU da $\mathrm{UFT}^{15}$ não conseguimos localizar nenhuma ação voltada para a comunidade acadêmica. Somente constam especificado os serviços e produtos informacionais como Empréstimo domiciliar informatizado para alunos, preceptores, residentes, professores e técnico-administrativos regulares da instituição; Consulta local para usuários cadastrados e a comunidade em geral; Empréstimo entre bibliotecas; Pesquisa de títulos no acervo informatizada e on line; Reserva on line de material bibliográfico emprestado; Renovação on line de empréstimos; Acesso aos periódicos da Capes e a outras bases de dados; Envio de e-mail automático aos usuários com avisos sobre empréstimos, devoluções e reservas disponíveis; Orientação na normalização de trabalhos acadêmicos, conforme a ABNT; Repositório institucional digital da produção intelectual científica de autores da UFT, incluindo trabalhos de conclusão de curso de graduação e especialização, dissertações de mestrado e teses de doutorado; Levantamento bibliográfico; Elaboração de ficha catalográfica; Treinamento de usuários e programas e conscientização para preservação do acervo. As redes sociais (Facebook, Instagram e Twitter) e canais de comunicação (YouTube) fazem parte de toda a instituição (BU UFT, 2020).

\section{CONSIDERAÇÕES FINAIS}

O levantamento dos dados permitiu um melhor entendimento da forma como as BU da região Norte do Brasil estão atendendo as necessidades informacionais de seus usuários no período de pandemia da COVID-19. Apesar de algumas BUs não estarem desenvolvendo ações voltadas para a capacitação de sua comunidade acadêmica, ainda há aquelas que vem apoiando as atividades acadêmicas através de atitudes inovadoras na sociedade contemporânea, como a oferta de serviços e produtos informacionais de forma diversificada (treinamentos virtuais, lives, webinar, entre outros). Percebemos que nos websites das bibliotecas da UFAC e do UFT apenas constam sinalizadas as atividades rotineiras como: pedido de ficha catalográfica, consulta ao acervo, empréstimo domiciliar, laboratório de pesquisa (pesquisa virtual), acesso ao Portal da Capes, acesso a livros e periódicos online, orientação técnica/trabalho acadêmico, comutação bibliográfica e treinamento de usuários.

Neste contexto, é necessário que as BU possam utilizar a tecnologia como uma aliada às inovações, de modo que possam ser um fator estratégico para aprimorar os serviços já existentes. Sendo assim, a inovação é um dos fatores primordiais para manter as bibliotecas universitárias atuantes considerando o atual cenário, uma vez que, a BU é um ambiente de troca de informação e tripé da universidade para o ensino, pesquisa e extensão, por isso ela deve considerar a inovação como um de seus principais fundamentos para o desenvolvimento dos serviços e produtos informacionais a ser ofertados à comunidade acadêmica. Observamos que há um desafio quando se trabalha inovação no contexto das BU, pois muitas vezes a dificuldade maior é dominar as tecnologias e, isto têm afastado muitos colaboradores que desenvolvem trabalhos voltados para a comunidade acadêmica usuária, pois não conseguem deixar de lado as crenças tradicionais para criar novos hábitos para aprimorar os serviços e produtos informacionais que as BU oferecem. Assim, sugere-se para trabalhos futuros realizar pesquisas sobre o cenário pós-pandemia para verificar se as BU da região Norte do Brasil continuaram com as ações citadas disponíveis para a comunidade acadêmica e sociedade em geral, bem

15 Consulta ao Website http://www.bc.ufrr.br/, realizada em 05/08/2020.

RDBCl: Rev. Dig. Bibliotec e Ci. Info. / RDBCl: Dig. J. of Lib. and Info. Sci. | Campinas, SP | v.18| e020032 | 2020 


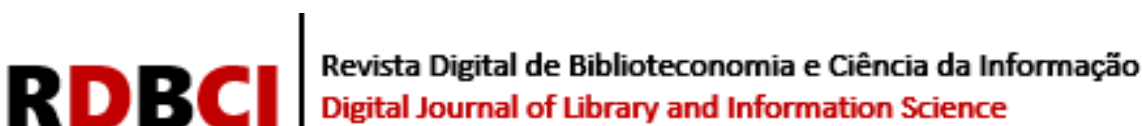

como se as demais BU que não haviam se adequado ao contexto de serviços adaptados às demandas da pandemia, assim o fizeram, demonstrando não apenas adaptação, mas também desenvolvimento de uma cultura de inovação. Infere-se ser esse tipo de cultura crucial para promover a inovação nas Bus, sendo responsável por promover os estímulos necessários para a adaptação, criação e mudança.

\section{REFERÊNCIAS}

ALMEIDA, A. Inovação e gestão do conhecimento. Rio de Janeiro: FGV, 2016.

ALMEIDA JÚNIOR, O. F. Biblioteconomia e sociedade. Brasília, DF: CAPES: UAB ; Rio de Janeiro, RJ : Departamento de Biblioteconomia, FACC/UFRJ, 2018. Disponível em: https://educapes.capes.gov.br/handle/capes/564473?fbclid=IwAR0wDyBT85tJuGKa2ygQ181 Ds XnOu-rQ2CZJ2-rxxalrKBfw7mf0ALfMwE. Acesso em: 28 jul. 2020.

ALMEIDA JÚNIOR, O. F. de. Mediação da informação: um conceito atualizado. In: BORTOLIN, S.; SANTOS NETO, J. A.; SILVA, R. J. da (org.). Mediação oral da informação e da leitura. Londrina: ABECIN, 2015.

\section{ALVES, A. P. M. Competência informacional e o uso ético da informação na produção} científica. São Paulo: Cultura Acadêmica Digital, 2018.

ALVES, A. P. M.; CASARIN, H. C. S.; FERNANDÉZ-MOLINA, J. Uso ético da informação e combate ao plágio: olhares para as bibliotecas universitárias brasileiras. Ciência da Informação e Biblioteconomia: Estudos, João Pessoa, v. 26, n. 1, p.115-130, abr. 2016. Disponível em: http://www.periodicos.ufpb.br/index.php/ies/article/view/27444\&gt. Acesso em: 6 ago. 2020.

ARAÚJO, E. A.; DIAS, G. A. A atuação do bibliotecário no contexto da sociedade da informação: os novos contextos de informação. In: OLIVERIRA, Marlene (org.). Ciência da Informação e Biblioteconomia: novos conteúdos e espaços de atuação. 2 ed. Belo Horizonte: Editora UFMG, 2011.

AZEVEDO, K. R. de, OGÉCIME， M. O papel do bibliotecário como mediador da informação na busca pelo letramento informacional. RDBCI: Revista Digital de Biblioteconomia e Ciência da Informação, Campinas, SP. v. 18, 2020. Disponível em:

https://periodicos.sbu.unicamp.br/ojs/index.php/rdbci/article/view/8654473. Acesso em: 19 jun. 2020

BELLUZZO, R. C. B.; KOBAYASHI, M. do C. M.; FERES, G. G. Competências na era digital: desafios tangíveis para bibliotecários e educadores. ETD - Educação Temática Digital, Campinas, SP, v. 6, n.1, p.81-99, dez. 2004. Disponível em: https://redib.org/Record/oai_articulo1621339-compet\%C3\%AAncias-na-era-digital-desafios-t ang\%C3\%ADveis-para-bibliotec\%C3\%A1rios-e-educadores. Acesso: 28 jul. 2020.

BRASIL. Ministério da Saúde. Sobre a doença: o que é covid-19. Brasília: DF, 2020. Disponível em: https://coronavirus.saude.gov.br/sobre-a-doenca. Acesso em: 28 jul. 2020. 


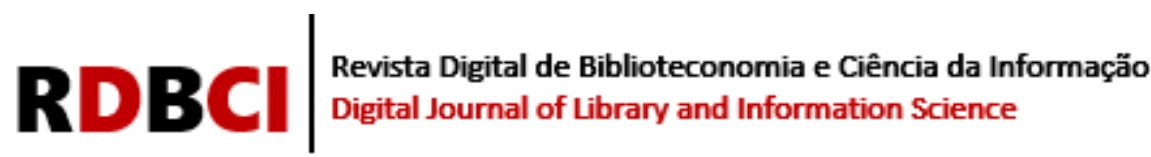

BRITO, T. R. de.; VITORINO, E. V. O bibliotecário e a mediação da informação no contexto das bibliotecas universitárias. Páginas arquivo e biblioteca. S.3, nº 8 (2017) 12-22. Disponível em: http://ojs.letras.up.pt/index.php/paginasaeb/article/view/3332. Acesso em: 6 ago. 2020.

COMISSÃO BRASILEIRA DE BIBLIOTECAS UNIVERSITÁRIAS. Recomendações da Comissão Brasileira de Bibliotecas - CBBU para elaboração de planejamento de reabertura das bibliotecas universitárias. São Paulo: Boa Vista, 2020. Disponível em: http://www.febab.org.br/cbbu/wp-content/uploads/2020/05/Recomenda\%C3\%A7\%C3\%B5es -14-de-maio-1.pdf. Acesso em: 28 jul. 2020.

COELHO NETO, J. T. Do paradigma do acervo para o paradigma da informação. In: SIMPÓSIO BRASIL-SUL DE INFORMAÇÃO, 1., 1996, Londrina. Anais... Londrina: UEL, 1996.

DUARTE, E. N.; AGUIAR, A. C. de; PINHEIRO, E. G.; CARVALHO, L. M.; NOGUEIRA, N. A cultura organizacional influenciando o comportamento do capital humano da biblioteca universitária. Informação \& Sociedade: Estudos, n. 2, v. 10 n.2 2000, 2000. Disponível em: https://brapci.inf.br/index.php/res/v/91401. Acesso em: 29 jul. 2020.

GOMES, H. F. A dimensão dialógica, estética, formativa e ética da mediação da informação. Informação e Informação, Londrina, v. 19, n. 2, p. 46 - 59, maio/ago. 2014. Disponível em: http://www.uel.br/revistas/uel/index.php/informacao/article/view/19994. Acesso em: 25 ago. 2020.

GOMES, M. A.; DUMONT, L. M. M. Possíveis relações entre o uso de fontes de informação e a competência em informação. TransInformação, Campinas, 27(2):133-143, maio/ago., 2015. Disponível em: https://www.scielo.br/pdf/tinf/v27n2/0103-3786-tinf-27-02-00133.pdf. Acesso em: 22 out. 2020.

FREIRE, P. Pedagogia da autonomia: saberes necessários à prática educativa. São Paulo: Paz e Terra, 2002.

JUNQUEIRA, C.; BALDRIGHI, R. M. ACOVID-19 e alguns retrados da internacionalização do ensino superior. Le Monde diplomatique Brasil. Acervo online, Brasil, 9 de maio de 2020. Disponível em: https://bit.ly/2IMbMhI. Acesso em: 25 ago. 2020.

LOURES, R. C. R. Inovação em ambientes organizacionais: teorias, reflexões e práticas. Curitiba: PR, Ibpex, 2006.

MARCONI, M. A., LAKATOS, E. M. Metodologia Científica. 5. ed. São Paulo: Atlas, 2008.

MANESS, J. M. Teoria da biblioteca 2.0: web 2.0 e suas implicações para as bibliotecas. Informação e Sociedade: Estudo, João Pessoa, v. 17, n. 1, p. 43-51, jan./abr. 2007. Disponível em: https://brapci.inf.br/_repositorio/2010/11/pdf_d1b75c96ad_0012775.pdf. Acesso em: 5 ago. 2020.

MINAYO, M. C. S. Pesquisa social: teoria, método e criatividade. Petrópolis: Vozes, 2002. 


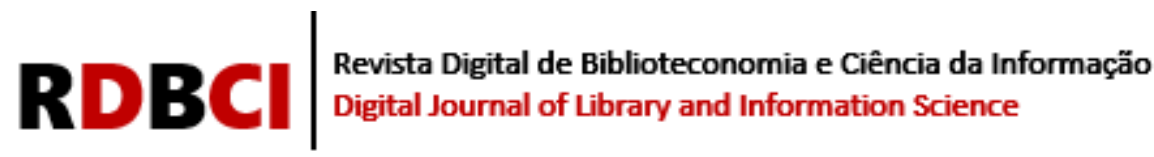

NASCIMENTO, R. B. do; TROMPIERI FILHO, N.; BARROS, F. G. F. Avaliação da qualidade dos serviços prestados nas unidades de informação universitárias.

Transinformação, Campinas, v.17, n.3, p.235-251, set./dez., 2005.

NEVES, J. J. F. A inovação nas bibliotecas universitárias brasileiras: identificando o potencial inovador. Dissertação (mestrado) - Universidade Federal de Santa Catarina, Centro de Educação, Programa Pós-Graduação em Ciência da Informação, Florianópolis, 2018. Disponível em: https://repositorio.ufsc.br/handle/123456789/190885. Acesso em: 5 ago. 2020.

PRADO, J. M. K. dos; CAVAGLIERI, M. A inovação para os bibliotecários de uma instituição de educação profissional: conhecendo o perfil para continuar inovando. REBECIN, v.3, n.2, p.93-108, jul./dez. 2016. ISBN 2358-3193. Disponível em: http://abecin.org.br/portalderevistas/index.php/rebecin. Acesso em: 12 ago. 2020.

SANTA ANNA, J. O bibliotecário em face das transformações sociais: de guardião a um profissional desinstitucionalizado. Revista ACB: Biblioteconomia em Santa Catarina, Florianópolis, v. 20, n. 1, p. 138-157, jan./abr., 2015. Disponível em:

https://revista.acbsc.org.br/racb/article/view/985. Acesso em: 29 jul. 2020.

SANTOS, C. A cultura organizacional das bibliotecas universitárias brasileiras. Pesquisa Brasileira em Ciência da Informação e Biblioteconomia, João Pessoa, v. 11, n. 2, p. 090-098, 2016. Disponível em: https://brapci.inf.br/index.php/res/download/42658. Acesso em: 29 jul. 2020.

ORGANIZAÇÃO DE COOPERAÇÃO E DESENVOLVIMENTO ECONÔMICO. Oslo Manual: Guidelines for collecting and interpreting innovation data. 2005. 3. ed. European Comission: OECD/OCDE. Disponível em: http://www.finep.gov.br/images/a-finep/biblioteca/manual_de_oslo.pdf. Acesso em: 5 ago. 2020.

SALES, F. de. O ambiente escolar e a atuação bibliotecária: o olhar da educação e o olhar da biblioteconomia. Encontro Bibli, Florianópolis, n 18, p.40-57, jul./dez. 2004.

RIOS, T. A. A presença da filosofia e da ética no contexto profissional. Revista Organicom, São Paulo, v. 5, n. 8, 2008. Disponível em: http://www.brapci.inf.br/_repositorio/2010/06/pdf_f564ebbc35 0011137.pdf\&gt. Acesso em: 7 ago. 2020.

TANUS, G. F. S.C; TARRAGÓ, M. Atuação e desafios das bibliotecas universitárias brasileiras durante a pandemia de COVID-19. Revista Cubana de Información en Ciencias de la, Salud. Disponível em: https://preprints.scielo.org/index.php/scielo/preprint/download/ 744/1007/1050. Acesso em: 12 ago. 2020.

ZANINELLI, T.; NOGUEIRA, C. A.; HORIMI, D. Inovação em serviços de inovação no contexto da Biblioteca Central da Universidade Estadual de Londrina (UEL): uma análise do ponto de vista dos nativos digitais. Revista Brasileira de Biblioteconomia e Documentação, v. 15, n. 1, 2019. ISSN 1980-6949. Disponível em: https://rbbd.febab.org.br/rbbd/article/view/1197. Acesso em: 5 ago. 2020. 


\section{RDBCI}

ZANINELLI, T. B.; NOGUEIRA C. A.; PERES, A. L. M. Biblioteca universitária: uma perspectiva teórica sobre inovações em serviços informacionais. RDBCI: Revista Digital Biblioteconomia e Ciência da Informação. ISSN-e 1678-765X, v. 17, 2019. Disponível em: https://periodicos.sbu.unicamp.br/ojs/index.php/rdbci/article/view/8652821. Acesso em: 14 ago. 2020. 


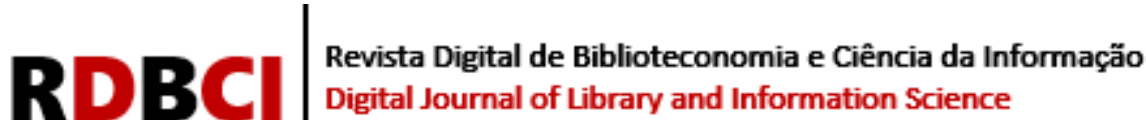

Artigo submetido ao sistema de similaridade 